\title{
Advanced Heat-Resistant TiAl (Nb,Cr,Zr)-Based Intermetallics with the Stabilized $\beta(T i)$-Phase
}

\author{
A.V. Kartavykh, M.V. Gorshenkov and A.V. Korotitskiy
}

\begin{abstract}
The paper represents a brief review of authors' research results and publications in the area of materials science and engineering of innovated lightweight heat-resistant TiAl-based intermetallic alloys. The system $\mathrm{TiAl}(\mathrm{Nb}, \mathrm{Cr}, \mathrm{Zr})$ under development is being considered as the advanced basis for the creation of TiAl-intermetallics of 3rd generation (TNM) TiAl(Nb,Mo)-like alloys, those being the most promising nowadays for an application in aviation jet engines design. This research is implemented within the frame of Federal Targeted Program for R\&D in Priority Areas of Development of the Russian Scientific and Technological Complex for 2014-2020 (Russian FTP for R\&D 2014-2020).
\end{abstract}

Keywords Structural intermetallics - Gamma-Titanium aluminides Multicomponent alloying $\cdot$ Heat resistance $\cdot$ Microstructure $\cdot$ High-Gradient float-zone processing $\cdot$ Aerojet turbine design

\section{Introduction}

In the review $[1,2]$ in 2013, we analyzed the state-of-the-art of materials science and technology of alloyed TiAl-intermetallics intended for extreme performances. In this review, we have predicted the technology transfer of these materials within the nearest future from the research stage to industrial application in aviation jet turbine-building corporations of the most developed countries. Indeed, the prospective at that time TiAl-intermetallics of the second generation have firstly been used in the low-pressure turbine (LPT) of serial engine GEnx-1B by General

A.V. Kartavykh · M.V. Gorshenkov $(\bowtie) \cdot$ A.V. Korotitskiy

National University of Science and Technology "MISIS", Moscow, Russia

e-mail: mvg@misis.ru

A.V. Kartavykh

e-mail: karta@korolev-net.ru

A.V. Korotitskiy

e-mail: akorotitskiy@gmail.com

(C) The Author(s) 2018

K.V. Anisimov et al. (eds.), Proceedings of the Scientific-Practical Conference

"Research and Development - 2016”, https://doi.org/10.1007/978-3-319-62870-7_38 
Electric for the equipping of long-range passenger aircraft Boeing 787 Dreamliner [3]. This breakthrough event, being almost synchronous with the review publication, has marked the new stage of TiAl-alloys application-their successful worldwide commercialization beginning. The strategy of application of the new class material in GEnx-1B turbine is rather cautious: from the lightweight alloy GE48-2-2 (of Ti-48Al-2Nb-2Cr at.\% composition) only 2 final LPT stages (turbine blade discs) are manufactured out of 5 in total, with the "softest" temperature service mode up to $650{ }^{\circ} \mathrm{C}$. Even such limited $\gamma$-TiAl application allows saving $180 \mathrm{~kg}$ per engine when compared to its precursor CF6-80 that best illustrates the cutting edge of $\gamma$-TiAl-alloys potential. The GEnx offers up to $15 \%$ better fuel consumption, which translates to $15 \%$ less $\mathrm{CO}_{2}$ emission [3]. However, the heat-resistant structural potential of the GE48-2-2 alloy is seemingly near to be exhausted and limited by the final LPT stages operating at the "softest" thermal and pressure modes. The following progress of $\gamma$-TiAl application in aircraft turbines requires the improvement of heat resistance and heat strength within the temperature range expanded towards $800{ }^{\circ} \mathrm{C}$ and higher. That led to the recent development of novel $\gamma$-TiAl-based alloys family, so-called TNM, i.e., TiAl(Nb,Mo)-like alloys which define the upper strength limit of titanium aluminides. Present paper represents the brief review of authors' research and publications in the area of properties engineering of $\mathrm{TiAl}(\mathrm{Nb}, \mathrm{Cr}, \mathrm{Zr})$ system. The intermetallics of this elemental system could offer the improved basis for the $\gamma$-TiAl materials creation of 3rd generation.

\section{The Concept of Development and Engineering the Composition of $\beta$-Stabilized Alloys}

The development of new generation of TiAl-intermetallics is being addressed to solve the problem of insufficient mechanical ductility, strength and stability of items at elevated temperatures, as well as adaptation of thermo-mechanical regimes of alloys processing (forging, rolling, etc.) to the technical specifications of industrial metalworking equipment.

Innovated gamma-titanium aluminides (TNM-like alloys) contain $42-46$ at.\% of aluminum, and up to 10-12 at.\% functional additives of transient metals, those stabilize the primary $\beta$-Ti phase (known also as B2 phase being in low-temperature ordered state). Apart from the obligatory $\mathrm{Nb}$, such $\beta$-stabilizers as $\mathrm{Mo}, \mathrm{Ta}, \mathrm{Zr}, \mathrm{Cr}$, $\mathrm{W}$, and V could be used. Such alloying leads to the retaining in solidified alloy of a relatively low volumetric fraction of residual B2-phase on the base of bcc lattice, which is ductile at high temperatures. The development concept and achieved properties of TNM-alloys are represented rather comprehensively in recent monograph [4] and in the review [5].

Historically for the first time the molybdenum was used as a $\beta$-stabilizing additive, which possesses utmost stabilizing activity (and the acronym $\mathrm{TNM}=\mathrm{TiAl}-\mathrm{Nb}-\mathrm{Mo}$ is originated from hence). However, it was revealed that Mo 
is worsening the corrosion resistance of $\gamma$-TiAl [6]. Nevertheless, the effect of $\beta$-stabilizers on the phase diagram transformation of an alloyed material was first studied using the Ti-43.5Al-4Nb-1Mo (at.\%) alloy as the typical example [7].

Authors in collaboration with the E.O. Paton Electric Welding Institute have elaborated the alternative alloy Ti-44Al-5Nb-3Cr-1.5Zr (at.\%) as the basic composition possessing enhanced corrosion stability due to a homogeneous distribution of anti-corrosion additives $\mathrm{Cr}$ and $\mathrm{Zr}$ through the constituting intermetallic phases. Particularly, this feature results also in high tribological and tribochemical resistance of the material at the high-temperature friction against heavily alloyed chromium steels [8].

Strong $\beta$-stabilizing doping results in a specific change of phase diagram and schematic of solid-state temperature-phase transformations of cast alloy with the participation of stabilized $\beta(\mathrm{Ti}) / \mathrm{B} 2$ phase in all technologically important domains (see Fig. 1a, b in comparison), that is the general trait of TNM-like alloys [7].

Key features of $\mathrm{TiAl}(\mathrm{Nb}, \mathrm{Cr}, \mathrm{Zr})$ diagram are the following: strong expansion of primary $\beta(\mathrm{Ti})$ phase area toward $\mathrm{Al}$ and lower temperatures; narrowing and shift of high-temperature $\alpha,(\alpha+\gamma)$ domains toward $\mathrm{Al}$, that leads to their excluding from the transformation pathway of the Ti-44Al- $5 \mathrm{Nb}-3 \mathrm{Cr}-1.5 \mathrm{Zr}$ composition (this pathway is marked by the arrow in Fig. 1b). The latter feature is defined substantially the specifics of microstructure forming of Ti-44Al-5Nb-3Cr- $1.5 \mathrm{Zr}$ in comparison with conventional compositions, including the Ti- $46 \mathrm{Al}-8 \mathrm{Nb}$ - precursor of our elaborating alloy. The mechanism of solid-state phase transformations of $\operatorname{TiAl}(\mathrm{Nb}, \mathrm{Cr}, \mathrm{Zr})$ could be simplified by the following sequence of stages:

$$
\beta(\mathrm{Ti}) \stackrel{(\mathrm{a})}{\longrightarrow} \beta(\mathrm{Ti}) / \mathrm{B} 2+\alpha \stackrel{(\mathrm{b})}{\longrightarrow} \mathrm{B} 2+\alpha_{2}-\mathrm{Ti}_{3} \mathrm{Al}+\gamma-\mathrm{TiAl}
$$

(a)

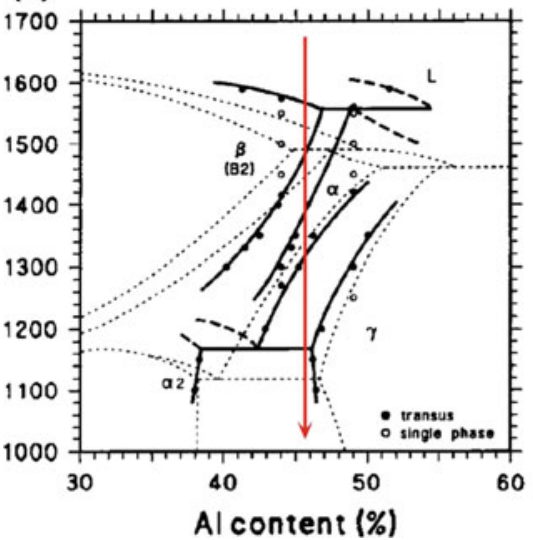

(b)

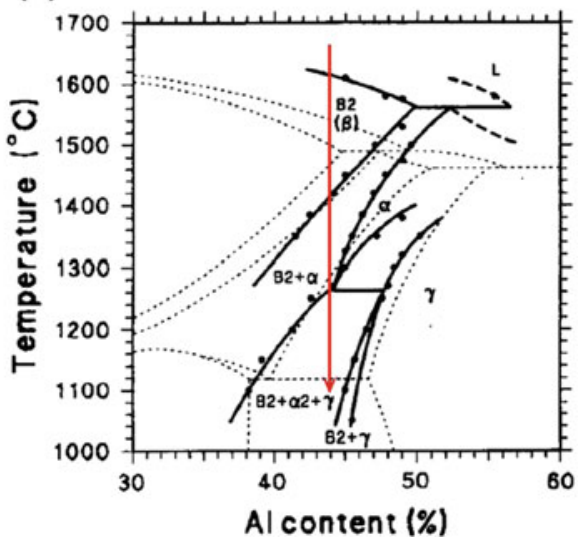

Fig. 1 The quasi-binary isopleths of systems TiAl-8at.\% $\mathrm{Nb}(\mathbf{a})$ and TiAl-10at.\%( $\mathrm{Nb}+\mathrm{Cr}+\mathrm{Zr})$ (b), where phase transformation pathways are marked by the arrows for Ti- $46 \mathrm{Al}-8 \mathrm{Nb}$ and Ti-44Al-5Nb-3Cr-1.5Zr (at.\%) alloys, respectively. The reference binary TiAl diagram is drawn with dotted lines 
It will be shown in Section 2.2 that stage (b) is characterized by two kinetic mechanisms, proceeding at cooling of the solid alloy generally in a nonequilibrium manner. That leads to the formation of $\gamma$-granular and $\left(\alpha_{2}-\mathrm{Ti}_{3} \mathrm{Al}+\gamma\right.$-TiAl)-lamellar substructures, being in coexistence with a residual B2-interlayer phase that is located along the boundaries of former transformed $\alpha$-grains:

$$
\begin{gathered}
\alpha \rightarrow\left(\alpha_{2}-\mathrm{Ti}_{3} \mathrm{Al}+\gamma-\mathrm{TiAl}\right)-\text { lamellar. } \\
\mathrm{B} 2 \rightarrow \gamma-\mathrm{TiAl}-\text { granular. }
\end{gathered}
$$

Since the volumetric fractions of these substructures are being formed as a result of nonequilibrium reactions, one can control them to some extent, applying different cooling rates and targeted thermal treatments [7, 9].

\section{Engineering the Microstructure and Mechanical Properties of $\operatorname{TiAl}(\mathrm{Nb}, \mathrm{Cr}, \mathrm{Zr})$}

\section{Microalloying with LaB}

It is well known that ductility of a multiphase intermetallic alloy could be improved by the grain refinement of isotropic equiaxed-granular microstructure [10]. For this purpose, one can apply the doping of $\mathrm{Nb}$-alloying titanium gamma-aluminides with boron-containing additives (usually with $\mathrm{TiB}_{2}$ ). That leads to the precipitation of micro/nanoscaled particles of monoboride-based solid solution $(\mathrm{Ti}, \mathrm{Nb}) \mathrm{B}$ within high-temperature domains of the phase diagram. These micro-crystals act as the local (point) seeds at the appearance of major intermetallic phases, leading to the numerous nucleation events and competitive statistic growth of fine equiaxed structural grains. This approach was earlier successfully applied, and the structure-forming mechanism was studied in detail by us in the different technological routes of the $\mathrm{TiAl}(\mathrm{Nb}) \mathrm{B}$ system solidification [11-13]. Additionally, the ductility can be enhanced by the lowering of interstitial embrittle impurity content of oxygen. Working with the complicated TNM-like system $\mathrm{TiAl}(\mathrm{Nb}, \mathrm{Cr}, \mathrm{Zr})$, we firstly applied joint doping with boron and rare-earth element (lanthanum) in the form of $\mathrm{LaB}_{6}$ compound [14]. That results in the ultra-fine microstructure formation of derivative alloys $\mathrm{Ti}-44 \mathrm{Al}-5 \mathrm{Nb}-2 \mathrm{Cr}-1.5 \mathrm{Zr}-0.4 \mathrm{~B}-0.07 \mathrm{La}$ and $\mathrm{Ti}-44 \mathrm{Al}-5 \mathrm{Nb}-1 \mathrm{Cr}-$ $1.5 \mathrm{Zr}-1 \mathrm{~B}-0.17 \mathrm{La}$ (at.\%) with the smallest achieved mean diameter of a structural grain of $30 \mu \mathrm{m}$, and low (300 wt.ppm) content of dissolved oxygen due to the joint effect of boron and lanthanum internal getter. The enhanced efficiency of $\mathrm{LaB}_{6}$ ligature application when compared to the microalloying with $\mathrm{TiB}_{2}$ is clearly seen in Fig. 2 from the comparison of microstructures refinement degree of $\operatorname{TiAl}(\mathrm{Nb}) \mathrm{B}$ vs. TiAl(Nb,Cr,Zr)B,La alloys. 

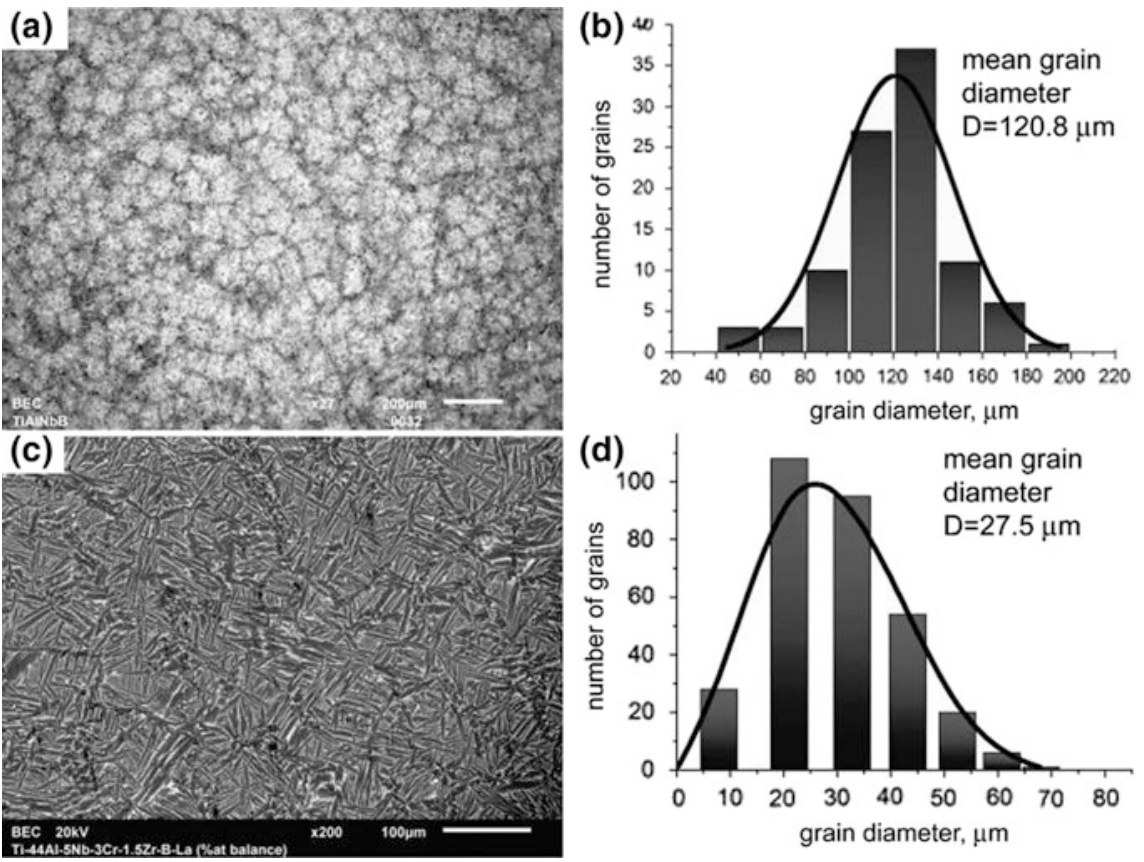

Fig. 2 Isotropic refined microstructures of the alloys (electron microscopy data), and the functions of their structural grains distribution by the diameter: $\mathbf{a}, \mathbf{b}-\mathrm{Ti}-44 \mathrm{Al}-7 \mathrm{Nb}-2 \mathrm{~B}$ (at.\%), micro-alloyed with $\mathrm{TiB}_{2}[11,12]$; c, d-Ti-44Al-5Nb-1Cr-1.5Zr-1B-0.17La (at.\%), with $\mathrm{LaB}_{6}$ [15]

The difference in microstructures of Ti-44Al-7Nb-2B and Ti-44Al-5Nb-1Cr-1.5Zr-1B-0.17La alloys, as displayed in Fig. 2, is related to the different phase-forming mechanisms at the microalloying of $\mathrm{TiAl}(\mathrm{Nb})$ and $\mathrm{TiAl}(\mathrm{Nb}$, $\mathrm{Cr}, \mathrm{Zr})$ systems with boron. In the $\mathrm{TiAl}(\mathrm{Nb})$ system the borides $(\mathrm{Ti}, \mathrm{Nb}) \mathrm{B}$ act as the seeds of high-temperature $\alpha$-phase at the transformation $\beta$ (Ti) $\rightarrow \alpha$ (Fig. 1a). When avoiding the domains $\alpha$ and $(\alpha+\gamma)$ in the system $\mathrm{TiAl}(\mathrm{Nb}, \mathrm{Cr}, \mathrm{Zr}$ ) (Fig. 1b), the ribbon-like borides display the activity in the more low-temperature field (B2 $\left.+\alpha_{2}+\gamma\right)$. Here they act as the centers of solid-state germination (seeding) of $\alpha_{2}-\mathrm{Ti}_{3} \mathrm{Al}$ phase, which is growing afterward through the matrix of basic $\gamma-\mathrm{TiAl}$ phase as lamellae (Fig. 3). This particular boride-induced mechanism of phase- and structure-forming in a TNM-like alloy have been studied and published by us for the first time in papers $[15,16]$. 

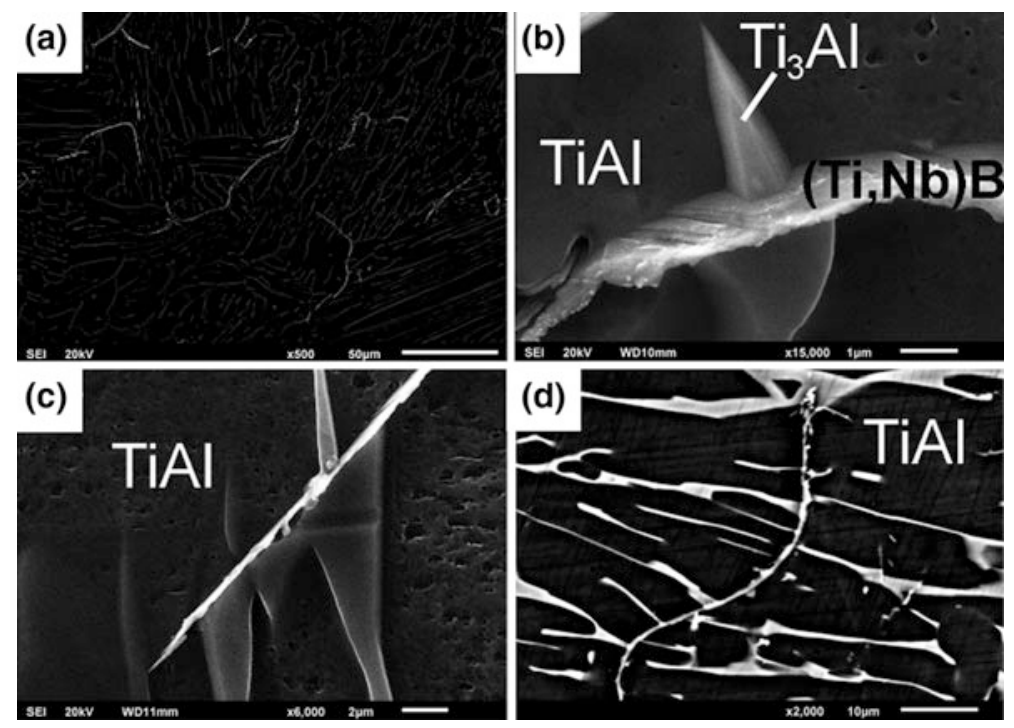

Fig. 3 Boride ribbons resolved in Ti-44Al-5Nb-2Cr-1.5Zr-0.4B-0.07La (a) and three consecutive stages of structure refining mechanism development: event of solid-state germination (seeding) of $\alpha_{2}-\mathrm{Ti}_{3} \mathrm{Al}$ phase on boride facet (b); morphological development of $\alpha_{2}$-laths and their growth through $\gamma$-TiAl matrix (c); formation of new grain boundary by elongated curved boride surrounded by fine $\gamma+\alpha_{2}$ phase structure inside the delimited grains (d). The electron microscopy micrographs $[15,16]$

\section{High-Gradient Float-Zone Processing}

Another fruitful approach in structure and properties engineering is using of controlling thermodynamic impact to the intermetallic system, i.e., solidification and cooling (annealing) of alloys in the strong directional fields - in magnetic or/and thermal ones. The directional solidification within thermal gradient is the most studied and therefore is most applicable.

At the directional solidification of TiAl-alloys by Bridgman method or by power-down technique $[11,12]$, the maximally achieved value of axial thermal gradient amounts to $50-70{ }^{\circ} \mathrm{C} / \mathrm{cm}$. In the Ti-46Al-8Nb (at.\%) alloy it results in the partial ordering of microstructure by the formation of elongated columnar primary $\beta$-grains aligned to the crystallization direction. Finally, the microstructure gets obtained consisting of elongated lamellar colonies, inside of which the separation of $\left(\alpha_{2}-\mathrm{Ti}_{3} \mathrm{Al}+\gamma\right.$-TiAl) lamellae in the low-temperature-phase domain (Fig. 1a) proceeds chaotically, in disagreement with the neighboring colony.

The application of float-zone technique (FZ) with a narrow zone allows increasing considerably the axial thermal gradient near the solid/melt interface. Induction $\mathrm{FZ}$ in an argon stream with the gradient of $300{ }^{\circ} \mathrm{C} / \mathrm{cm}$ was applied by authors firstly to the TNM-like alloy Ti-44Al-5Nb-3Cr-1.5Zr (at.\%) in papers [17, 18], and led to the promising results. Let us consider them in more details. 
Figure 4a displays the irregular microstructure of initial virgin ingot of Ti-44Al-5Nb-3Cr-1.5Zr, which was manufactured by semi-continuous electron-beam synthesis/casting technique from the pure metals [14]. Basic phase $\gamma$-TiAl is imaged here by gray, $\alpha_{2}-\mathrm{Ti}_{3} \mathrm{Al}$ - by black and $\mathrm{B} 2$ - as bright phase. For comparison in Fig. 4b the oriented duplex (lamellar-granular) microstructure is given of the same alloy after FZ-processing. It consists of the axially aligned lamellar $\alpha_{2}-\mathrm{Ti}_{3} \mathrm{Al}+\gamma$-TiAl matrix (80\% volumetric), granular $\gamma$-TiAl microstructure (15\%), and $5 \%$ of bright inter-granular layers of stabilized $\beta$-Ti (B2) phase. Thus, the sub-structural volumetric formula of the FZ-processed Ti-44Al-5Nb-3Cr-1.5Zr alloy can be expressed as $\left(\gamma+\alpha_{2}\right) / \gamma / \mathrm{B} 2=85: 15: 5$.

The lamellar matrix is magnified in Fig. $4 \mathrm{~d}$, being consisted of alternating lamellae of $\gamma$-TiAl and $\alpha_{2}-\mathrm{Ti}_{3} \mathrm{Al}$ phases of sub-micron thicknesses, aligned with the direction of the high-temperature gradient. Figure $4 \mathrm{c}$ represents the magnified
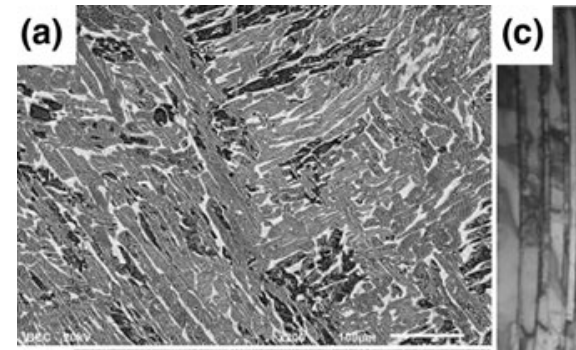

(b)

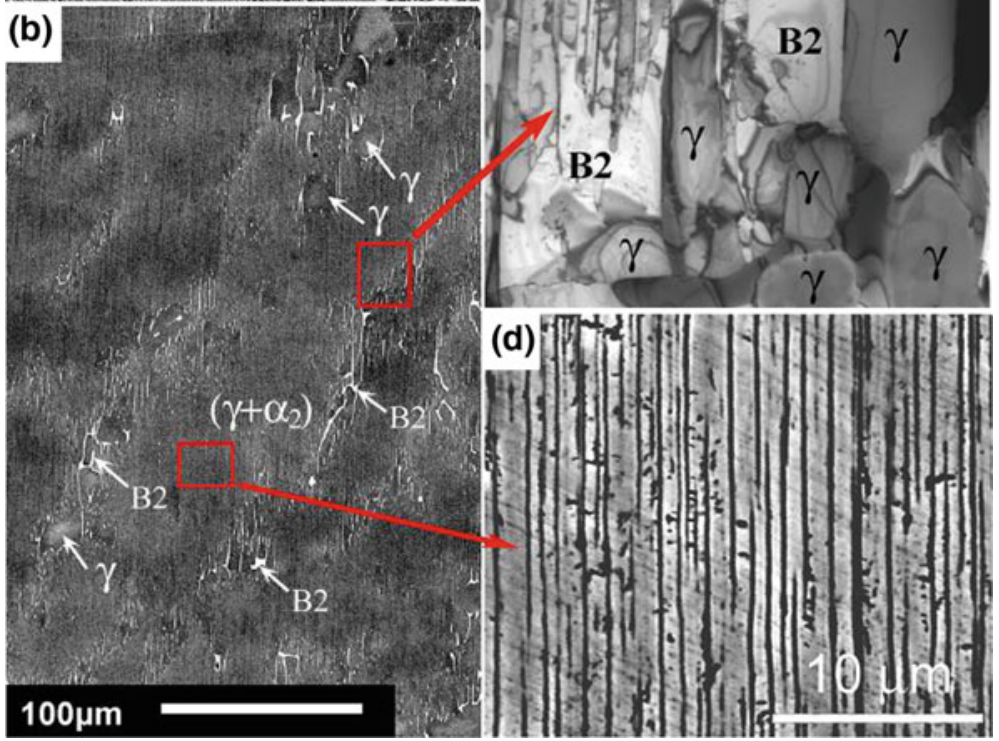

Fig. 4 a-Irregular microstructure of cast Ti-44A1-5Nb-3Cr-1.5Zr; b-ordered microstructure of the alloy after FZ-processing; $\mathbf{c}$-magnified transition between the lamellar area and $(\gamma+$ B2) interlayer; $\mathbf{d}$-magnified axially aligned $\left(\gamma+\alpha_{2}\right)$ lamellae. The electron microscopy micrographs after $[17,18]$ 
transient area between the lamellar and $\gamma$-granular fractions, where the details of structural transition and "relaxing" grains of B2-interlayer are seen; the latter are ductile at elevated temperature. Evidently, as a result of FZ-processing, the microstructure of the alloy is cardinally modified, refined and ordered at the conservation of an unchanged set of constituting phases. Therefore, the microstructural engineering is carefully being performed.

The duplex structure, represented in general view in Fig. 4b was formed within the low-temperature domain (B2 $+\alpha_{2}+\gamma$ ) of phase diagram (Fig. 1b) during the nonequilibrium cooling under high thermal gradient impact. The gradient promotes the ordering, "pooling" of growing $\alpha_{2}+\gamma$ lamellae along the ingot axis at their formation from $\alpha$-phase according to the reaction (2). The $\gamma$-granular fraction is being formed at the transformation of B2 phase according to reaction (3) and is situated along the former boundaries of columnar textured $\alpha$-grains, those elongated as well in the thermal gradient direction. The completion degree of this reaction depends on the cooling rate of the alloy within $\left(\mathrm{B} 2+\alpha_{2}+\gamma\right)$ area of phase diagram after FZ passing. Therefore it depends on the zone movement rate. Thus, the relative volumetric ratio of sub-structural fractions $\left(\gamma+\alpha_{2}\right) / \gamma / \mathrm{B} 2$ could be optimized rather easily by the kinetic way, i.e., by the zone movement rate variation.

The ordered microstructure with optimized $\left(\gamma+\alpha_{2}\right) / \gamma / \mathrm{B} 2$ volumetric quotas (Fig. 4b) possesses more balanced properties when compared to the cast material. Fine lamellar matrix (Fig. 4d) is responsible for the improved strength and creep especially under axial loading. Meanwhile, the heat resistance and plasticity get enhanced thanks to the incorporated interlayers composed of $\gamma$-grains and ductile B2-phase (Fig. 4c). At the expense of limited elastic mobility of $\gamma$-grains within the medium of B2-phase, such interlayers promote the relaxation of stresses in basic lamellar structure, thus raising the high-temperature threshold of its destruction.

The specimens of virgin and structurally modified alloy Ti-44Al-5Nb-3Cr-1.5Zr were comparatively examined by the uniaxial compression along the ingot's axis at the temperatures from 750 to $1050{ }^{\circ} \mathrm{C}$. The results of high-temperature tests are given in Figs. 5a-d, illustrating the comparative degradation of physical-mechanical properties of the alloys vs. temperature. FZ-processing led to substantial improvement of deformability (Fig. 5a), an increase of yield strength (Fig. 5b) and Young's modulus (Fig. 5c) at the same temperatures. At the same loads, the creep resistance rises. Exemplarily, under the load of $200 \mathrm{MPa}$ the first signs of creep of FZ-alloy appear only at $950{ }^{\circ} \mathrm{C}$ (Fig. 5d). In other words, FZ-alloy possesses the identical level of deformability parameters at the temperatures by $100-150{ }^{\circ} \mathrm{C}$ higher when compared to cast material. Thus the upper-temperature limit of Ti-44Al-5Nb-3Cr-1.5Zr structural applicability could be expanded from 750 to $800{ }^{\circ} \mathrm{C}$ towards $900-950{ }^{\circ} \mathrm{C}$. 

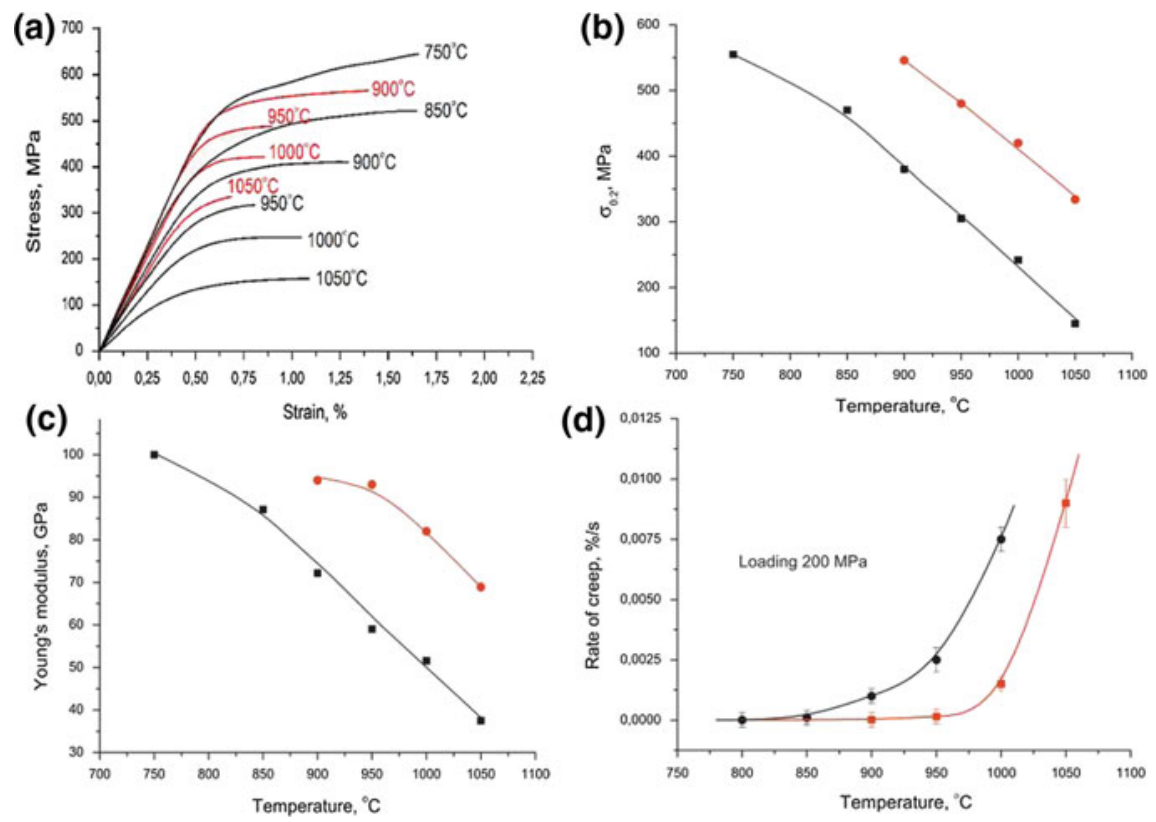

Fig. 5 Plots of physical-mechanical properties of cast (in black) and FZ-processed (in red) alloys vs. temperature [18]: a —axial deformation curves; $\mathbf{b}$ - yield strength; $\mathbf{c}-$ Young's modulus; $\mathbf{d}-$ creep rate

\section{Conclusions}

We have demonstrated in laboratory scale that the system $\mathrm{TiAl}(\mathrm{Nb}, \mathrm{Cr}, \mathrm{Zr})$ under development could represent the advanced basis for the creation of TiAl-intermetallics of third generation, those being the most promising nowadays for an application in aviation jet engines design. Considering the Ti-44Al-5Nb-3Cr-1.5Zr (at.\%) composition, the features of phase diagrams and structure formation have been discussed of a new class of $\gamma$-TiAl-intermetallics with stabilized $\beta$ phase, those allow applying the new effective principles of the necessary structural properties creation of the material. The brief review of authors' innovative research and publications is presented in the field of engineering the new types of heat-resistant microstructures in gamma-titanium aluminides by joint microalloying with boron and lanthanum, and by the high-gradient float-zone processing application. The experimental specimens of microstructured alloy possess both increased high-temperature strength, and creep resistance at the uniaxial loading, thus exhibiting the substantial extension of thermal service range when applying $\gamma$-TiAl in turbine blades and other crucial components of aircraft jet engines design. 


\section{References}

1. Kartavykh, A.V., Kaloshkin, S.D., Cherdyntsev, V.V. et al.: Application of microstructured intermetallides in turbine manufacture. Part 1: present state and prospects (a review). Inorg. Mater.: Appl. Res. 4 № 1, 12-20 (2013)

2. Kartavykh, A.V., Kaloshkin, S.D., Cherdyntsev, V.V. et al.: Application of microstructured intermetallides in turbine manufacture. Part 2: problems in development of heat-resistant alloys based on TiAl (a review). Inorg. Mater.: Appl. Res. 4 №1, 36-45 (2013)

3. The GEnx Commercial Aircraft Engine (2015). [Electronic resource] URL. http://www. geaviation.com/commercial/engines/genx/. Accessed 25 Oct 2016

4. Appel, F., Paul, J.D.H., Oering, M.: Gamma titanium aluminide alloys: science and technology, p. 745. WILEY-VCH, Weinheim (2011)

5. Clemens, H., Mayer, S.: Design, processing, microstructure, properties, and applications of advanced intermetallic TiAl alloys. Adv. Eng. Mater. 15(4), 191-215 (2013)

6. Brotzu, A., Felli, F., Pilone, D.: Effect of alloying elements on the behaviour of TiAl-based alloys. Intermetallics 54, 176-180 (2014)

7. Schwaighofer, E., Clemens, H., Mayer, S., et al.: Microstructural design and mechanical properties of a cast and heat treated intermetallic multi-phase $\gamma$-TiAl based alloy. Intermetallics 44, 128-140 (2014)

8. Kartavykh, A.V., Gorshenkov, M.V., Danilov, V.D. et al.: Tribochemistry of dry-sliding wear of structural $\mathrm{TiAl}(\mathrm{Nb}, \mathrm{Cr}, \mathrm{Zr}) \mathrm{B}, \mathrm{La}$ intermetallics family against the chromium steel. Tribol. Int. 90, 270-277 (2015)

9. Erdely, P., Werner, R., Schwaighofer, E. et al.: In-situ study of the time-temperature-transformation behaviour of a multi-phase intermetallic $\beta$-stabilised TiAl alloy. Intermetallics. 57, 17-20 (2015)

10. Morris, M.A., Leboeuf, M.: Grain-size refinement of $\gamma$-Ti-Al alloys: effect on mechanical properties. Mater. Sci. Eng. A224, 1-11 (1997)

11. Kartavykh, A.V., Tcherdyntsev, V.V., Gorshenkov, M.V. et al.: Tailored microstructure creation of TiAl-based refractory alloys within VGF solidification. Mater. Chem. Phys. 141 (2-3), 643-650 (2013)

12. Kartavykh, A.V., Tcherdyntsev, V.V., Gorshenkov, M.V. et al.: Microstructure engineering of TiAl-based refractory intermetallics within power-down directional solidification process. J. Alloys Compd. 586, S180-S183 (2014)

13. Kartavykh, A.V., Gorshenkov, M.V., Tcherdyntsev, V.V. et al.: On the state of boride precipitates in grain refined TiAl-based alloys with high $\mathrm{Nb}$ content. J. Alloys Compd. 586, S153-S158 (2014)

14. Kartavykh, A.V., Asnis, E.A., Piskun, N.V. et al.: Lanthanum hexaboride as advanced structural refiner/getter in TiAl-based refractory intermetallics. J. Alloys Compd. 588, 122126 (2014)

15. Kartavykh, A.V., Gorshenkov, M.V., Podgorny, D.A.: Grain refinement mechanism in advanced $\gamma$-TiAl boron-alloyed structural intermetallics: the direct observation. Mater. Lett. 142, 294-298 (2015)

16. Kartavykh, A.V., Gorshenkov, M.V., Podgorny, D.A.: The direct observation of grain refinement mechanism in advanced multicomponent $\gamma$-TiAl based structural intermetallics doped with boron. In: Polychroniadis, E.K. et al. (eds.) 2nd International Multidisciplinary Microscopy and Microanalysis Congress. Springer Proc. in Physics. 164, 175-181 (2015)

17. Kartavykh, A.V., Asnis, E.A., Piskun, N.V. et al.: Microstructure and mechanical properties control of $\gamma-\mathrm{TiAl}(\mathrm{Nb}, \mathrm{Cr}, \mathrm{Zr})$ intermetallic alloy by induction float zone processing. J. Alloys Compd. 643, S182-S186 (2015)

18. Kartavykh, A.V., Asnis, E.A., Piskun, N.V. et al.: A promising microstructure/deformability adjustment of $\beta$-stabilized $\gamma$-TiAl intermetallics. Mater. Lett. 162, 180-184 (2016) 
Open Access This chapter is licensed under the terms of the Creative Commons Attribution 4.0 International License (http://creativecommons.org/licenses/by/4.0/), which permits use, sharing, adaptation, distribution and reproduction in any medium or format, as long as you give appropriate credit to the original author(s) and the source, provide a link to the Creative Commons license and indicate if changes were made.

The images or other third party material in this chapter are included in the chapter's Creative Commons license, unless indicated otherwise in a credit line to the material. If material is not included in the chapter's Creative Commons license and your intended use is not permitted by statutory regulation or exceeds the permitted use, you will need to obtain permission directly from the copyright holder.

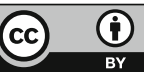

